\title{
The collagenic architecture of human dura mater
}

\author{
Laboratory investigation
}

\author{
Marina Protasoni, M.D., Ph.D., ${ }^{1}$ Simone Sangiorgi, M.D., Ph.D., ${ }^{2}$ \\ Andrea Cividini, M.D., ${ }^{2}$ Gloria Tiffany Culuvaris, M.D., ${ }^{1}$ Giustino Tomei, M.D., 2 \\ Carlo Dell'Orbo, M.D., ${ }^{1}$ Mario Raspanti, B.D., ${ }^{1}$ Sergio Balbi, M.D., ${ }^{2}$ \\ and Marcella Reguzzoni, B.D. ${ }^{1}$
}

Departments of ${ }^{1}$ Human Morphology and ${ }^{2}$ Surgery, Neurosurgical Unit, University of Insubria, Varese, Italy

\begin{abstract}
Object. Human dura mater is the most external meningeal sheet surrounding the CNS. It provides an efficient protection to intracranial structures and represents the most important site for CSF turnover. Its intrinsic architecture is made up of fibrous tissue including collagenic and elastic fibers that guarantee the maintenance of its biophysical features. The recent technical advances in the repair of dural defects have allowed for the creation of many synthetic and biological grafts. However, no detailed studies on the 3D microscopic disposition of collagenic fibers in dura mater are available. The authors report on the collagenic 3D architecture of normal dura mater highlighting the orientation, disposition in 3 dimensions, and shape of the collagen fibers with respect to the observed layer.

Methods. Thirty-two dura mater specimens were collected during cranial decompressive surgical procedures, fixed in $2.5 \%$ Karnovsky solution, and digested in $1 \mathrm{~N} \mathrm{NaOH}$ solution. After a routine procedure, the specimens were observed using a scanning electron microscope.

Results. The authors distinguished the following 5 layers in the fibrous dura mater of varying thicknesses, orientation, and structures: bone surface, external median, vascular, internal median, and arachnoid layers.

Conclusions. The description of the ultrastructural 3D organization of the different layers of dura mater will give us more information for the creation of synthetic grafts that are as similar as possible to normal dura mater. This description will be also related to the study of the neoplastic invasion. (DOI: 10.3171/2010.12.JNS101732)
\end{abstract}

\section{Key Words • dura mater • scanning electron microscope • Othani maceration protocol • collagen fiber}

$\mathrm{O}$ NE of the earliest detailed morphological macroscopic descriptions of dura mater was by Vesalius in the 16th century in his De Humani Corporis Fabrica:

Dura cerebri comonstrat membranam adhuc illesam, neque aliqua ex parte pertusam, vulnuratam ue. Quamuis interim ipsius membrane vincula divulsimus, quae per capitis suturas ad membranam efformanda porriguntur. Atquae cum his fibris pariter vascula sunt effracta, quae per calvariae foraminula et sutures deducta, ipsi durae membranae, ac illi qua calvaria succingitur, communes censentur. [Dura mater is a continuous membrane, without any holes or openings. It is strictly adherent to the cranial structures. Its vessels are enclosed in the dura mater itself and can also enter the skull through bone foramina. $]^{3}$

These words, borrowed from one of the first scientific reports that would form the basis of later morphological studies, describe the dura mater and its structure very well. The dura mater, also called pachymeninx, forms a continuous collagenic sheet surrounding intracranial and spinal nervous structures. It provides efficient protection to the CNS against infections and traumatic injuries acting on the skull and spine.

Dura mater is firmly attached to the cranial vault and the skull base and reaches the foramen magnum, where it divides into 2 layers. The external layer constitutes the periosteum of the spinal canal, and the internal layer creates the meningeal covering of the spinal cord and the first tract of spinal nerve roots.

Folds of dura mater form the falx cerebri and tentorium cerebelli, providing a macroscopic division of intracranial spaces into supratentorial (right and left) and infratentorial compartments. Some other lesser folds are also present, namely the sellar floor, olfactory tent, and falx cerebelli.

Due to some arachnoid specialization called "Pacchioni granulation" and venous bridging cortical vessels, the dura mater is highly involved in CSF resorption and, consequently, in the maintenance and balance of intracranial pressure.

Viewed through a light microscope, 3 different layers of dura mater have been described. ${ }^{30}$ The outer dural border layer, which is $2 \mu \mathrm{m}$ thick, is the thinnest layer and is composed of fibroblasts with long cellular extensions and collagen and elastic fibers. The median layer, called the fibrous dura, is vascularized and its thickness varies depending on location (that is, the cranial or spinal region). The innermost layer, the dural border cell layer, ${ }^{16}$ 
is $8 \mu \mathrm{m}$ thick and is composed strictly of cells that adhere to arachnoid trabeculae.

Viewed from the outside, the bundles of collagen fibers are macroscopically oriented throughout the cranial convexity; due to the mechanical forces acting from inside and outside on the skull, the orientation follows the trajectories of the spongy bone. ${ }^{9}$ As a consequence, focal mechanical forces are distributed in a more extended area. This macroscopic disposition varies greatly depending on the location in the cranial region and the age and the development of the skull.

In neurosurgical practice, dural defects may be due to trauma, inflammatory or neoplastic processes, surgical procedures, or congenital abnormalities. In these circumstances, the need to close dural defects has prompted a quest for studying the microscopic structures and physical properties of the dura mater with the aim of making an "ideal" substitute.

An "ideal" graft is one that can reproduce the biomechanical characteristics of host dura mater to avoid any inflammatory response or neurotoxicity. Moreover, the graft should be resorbed to form a newly developed dura with the same fiber architecture as in normal conditions. There should be no adhesion to surrounding tissues, and the graft should be resistant to tearing forces, should be watertight, free of prions and viruses, and easy to handle and apply. ${ }^{11}$

For these reasons, beginning in the 20th century many natural and synthetic dural substitutes have been introduced in clinical practice, and over time, numerous experimental studies have been conducted on these products to examine their physiochemical properties and integration with normal dura mater. Autografts, allografts, xenografts, and nonabsorbable and absorbable polymer sheets have been used. Some complications have been reported, such as chronic infections, intense cellular reaction and thick encapsulation, hematoma or foreign body reaction, and Creutzfeldt-Jacob disease. Among all these substitutes, resorbable collagen implants seem to be best able to replicate the physiological composition of dura mater and to guarantee a natural scaffold for integration and replacement of the entire graft with normal dura mater.

Collagen has many properties; because it is a resorbable protein, its degradation can be controlled by crosslinking. Collagen is hemostatic and able to induce cellular growth with a final tissue reconstruction. The major problem of these types of substitutes is the risk of an immunological or severe inflammatory reaction: the collagen should be highly purified, not pyrogenic, and without telopeptides. Hence, various chemical or physical procedures have been used to inactivate viruses, bacteria, and prions. To date, many collagen-based dural substitutes have been synthesized and tested in experimental in vitro and in vivo studies, and data on the integration with normal tissue are available. ${ }^{2,4-6,8,10,12,13,15-19,25,31,32}$

Despite the large number of these dural substitutes and the growing interest in finding "ideal" dural substitutes that can mimic the physiological structure of human dura mater and avoid complications, there have been few studies of the microscopic morphology, disposition, and $3 \mathrm{D}$ architectural distribution of the collagenic component in human dura mater. ${ }^{1,23,24,33}$ Our study aims to describe the microscopic 3D structural features and patterns of the collagen fibers as principal components of dura mater architecture.

\section{Methods}

All procedures were performed observing common guidelines in dealing with private personal data. Thirtytwo specimens of dura mater that could not be reimplanted were collected during decompressive surgical procedures performed in patients with uncontrollable intracranial pressure or posttraumatic injuries.

The size of the specimens was constant (Fig. 1 lower; size $=1.25 \mathrm{~cm}^{2}$ ), and the shape was trapezoidal with squared angles to guarantee the correct orientation. The specimens were taken from frontal, temporal, parietal, and occipital (8 specimens of each) convexities and immediately immersed in Karnovsky solution $(0.25 \%$ glutaraldehyde and $0.25 \%$ paraformaldehyde, in $0.1 \mathrm{M} \mathrm{Na}-$ cacodylate buffer at $\mathrm{pH}$ 7.2). The collected specimens were then left in fixative solution for 2 weeks; the solution was changed after 1 week. After the fixation process, each specimen was cut with a razor blade, and from each specimen 3 more were obtained: one to observe the bone surface, another to study the thickness, and the last to examine the arachnoid surface (Fig. 1 lower [b]). All these specimens were then immersed in a solution of $1 \mathrm{~N}$ $\mathrm{NaOH}$. The solution was changed daily to wash away the digested organic tissue.

All specimens were dehydrated in graded alcohol, critical point dried in an Emitech K850 CPD apparatus, mounted on aluminum stubs on adhesive film, and coated with $10 \mathrm{~nm}$ of gold in an Emitech K250 sputter-coater. Because of the size of some specimens, metallic bridges were needed to maintain a good conduction over the entire stub. The specimens were then observed using a Philips XL30 FEG scanning electron microscope at $10 \mathrm{kV}$.

\section{Three-Dimensional Micrometric Analysis}

All the samples were analyzed using scanning electron microscopy 3D micrometric analysis software, and the data were recorded. The scanning electron microscopy stereo images were fed to proprietary surface reconstruction software, whose implementation details are discussed in detail elsewhere. ${ }^{14}$ The software reads a stereo-pair of scanning electron microscopy micrographs, selects a point in the first picture and identifies the same in the second picture, computes the height of all the key points thus identified in both micrographs, and connects the points obtained using a Delaunay triangulation to reconstruct the spatial shape of the original specimen.

All VRML (virtual reality modeling language) files were studied using a second proprietary software program (MicroMetric version 1.1.3, 2004, M. Raspanti) that yields mathematically correct 3D measurements. The obtained quantitative data were evaluated using SPSS statistical software.

\section{Digital Image Directional Analysis}

We conducted a computerized colorimetric investi- 
gation of the specimens, and we evaluated the orientation of the collagen fibers. The quantification was performed automatically by obtaining a colored map that showed the distribution of fibers along different orientations. Specimens were analyzed at $\times 4000$ to allow a precise recognition of single fibers and to easily follow their course along the investigated layers.

\section{Results}

Scanning electron microscopic observation of the thickness of dura mater allowed us to distinguish 5 different layers as follows (Fig. 1 upper): one facing the inner table of the cranial bone (the bone surface layer) $(\alpha)$, the external median layer $(\beta)$, the vascular layer $(\gamma)$, the internal median layer $(\delta)$, and the layer facing the arachnoid membrane $(\varepsilon)$.

To provide a detailed description of dura mater collagenic composition, we investigated all the areas represented in Fig. 1 lower (a). The specimens were kept as represented and their orientation was maintained (Fig. 1 lower $[b])$.

At low magnifications, the layers were distinguishable on the basis of the reciprocal orientation and shape of their collagen fibers, and at high magnification by the presence of certain specialized structures. They are described in detail below.

\section{Bone Surface Layer}

At low magnification $(\times 300)$ at the level of the surface facing the bone, the dura mater appears to be flat, without any significant corrugation even if the imprints left by meningeal arteries and veins are sometimes visible (Fig. 2A asterisk). In some cases, we can also observe the "organic collagenic skeleton" of larger vessels lying on the surface of the dura mater.

The thickness of the bone surface layer can be seen in a transverse section and measures approximately $20 \mu \mathrm{m}$ (Fig. 2B). At a higher magnification, the collagenic composition of this layer appears to be made up of 2 different components. The upper component is characterized by a thin net of interlaced single collagen fibers without any particular orientation (Fig. 2C), and the lower component is formed by collagen fibers organized in larger bundles that run parallel to each other and that maintain more or less the same orientation (Fig. 2D). When observed in detail, these fibers reveal their characteristic $67-\mathrm{nm}$-long stripes.

In the transverse and oblique sections of this layer, it is possible to observe the relationships with the underlying external median layer. The shape of collagen bundles lying between the external median layer and the bone surface layer is convoluted, tortuous, and without any constant orientation (Fig. 2E arrow). These bundles differ from those in the bone surface layer and from those in the external median layer. They most likely represent the extracellular matrix structures that provide connection between these 2 layers.

The collagen fibers of the bone surface layer may have some specialized organization. Focal aggregations of disorganized collagen fibers are clearly visible among regularly directed underlying fibers (Fig. 3A). At
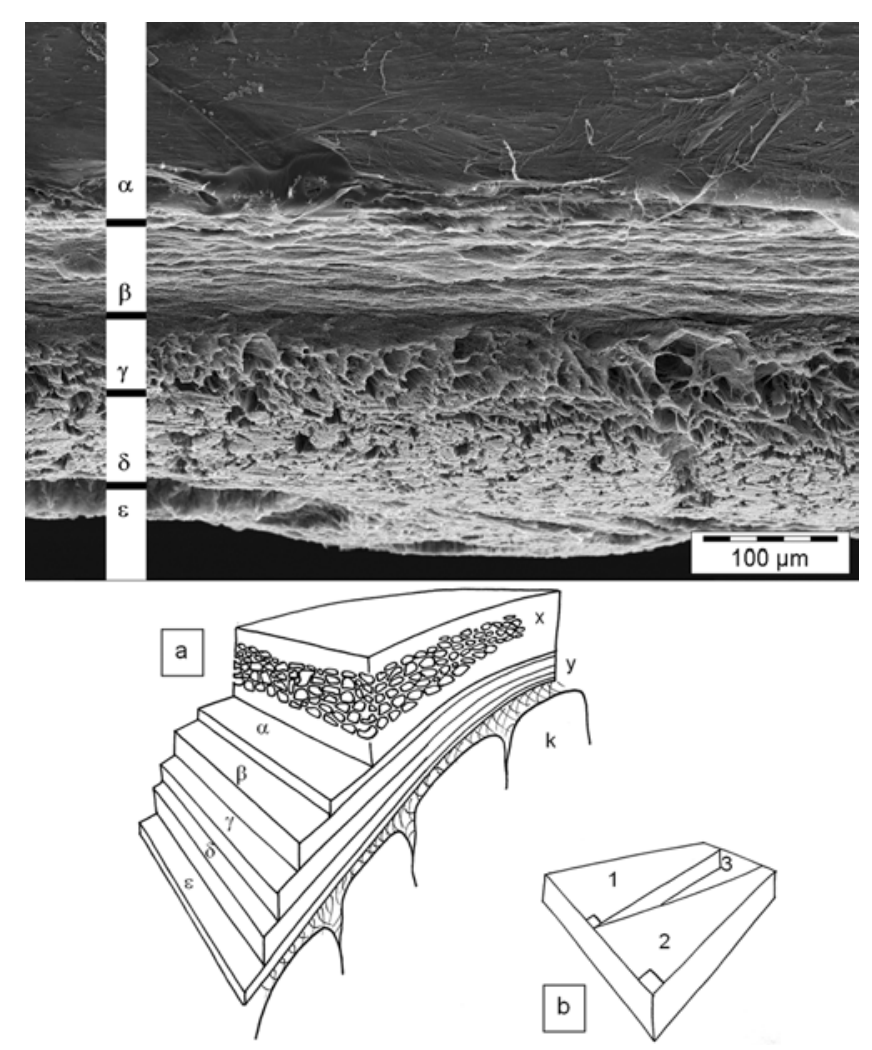

Fig. 1. Upper: Transverse section of the dura mater seen by scanning electron microscopy. At low magnification, it is possible to distinguish 5 different layers depending on the orientation with respect to the bone. The most external is in direct contact with the bone and is called the bone surface layer $(\alpha)$. The fibrous dura recognized by the anatomists as the median layer comprises the external median layer $(\beta)$, the vascular layer $(\gamma)$, and the internal median layer $(\delta)$. The most internal layer in direct contact with dural border cells and facing the arachnoid mater is called the arachnoid layer $(\varepsilon)$. Lower: The scheme is divided into 2 parts. The first (a) represents each layer described in the upper panel and is examined in the study as follows: the bone surface layer $(\alpha)$, the external median layer $(\beta)$, the vascular layer $(\gamma)$, the internal median layer $(\delta)$, and the arachnoid layer $(\varepsilon)$. The bone of the calvaria $(x)$, the arachnoid membrane $(\mathrm{y})$, and the brain cortex $(\mathrm{k})$ are also shown. The second part (b) represents a single specimen divided into 3 lesser specimens for the study: the first (1) is the specimen used to study the bone surface layer, the second (2) to study the arachnoid layer, and the third (3) to study the thickness of the dura mater.

high magnification, these fibers reveal a characteristic $180^{\circ}$-angled shape (Fig. 3B). Collagen bundles also line some lacunae that represent the loci usually occupied by fibroblasts (Fig. 3C). At high magnification, these lacunae appear to be partially covered by a thin sheet of interlaced, angled collagen fibers (Fig. 3D and E). At the bottom of these lacunae, a well-organized collagenic sheet of larger bundles is visible. Digital image analysis has demonstrated that almost all of these fibers are oriented in one direction (details below). Thin collagen fibers can also be seen extending between the walls of the lacunae.

\section{External Median Layer}

The most external subdivision of the so-called "fibrous dura" (Fig. 4A) median layer contains collagen bundles that seem to be oriented in one direction $(\beta)$, 


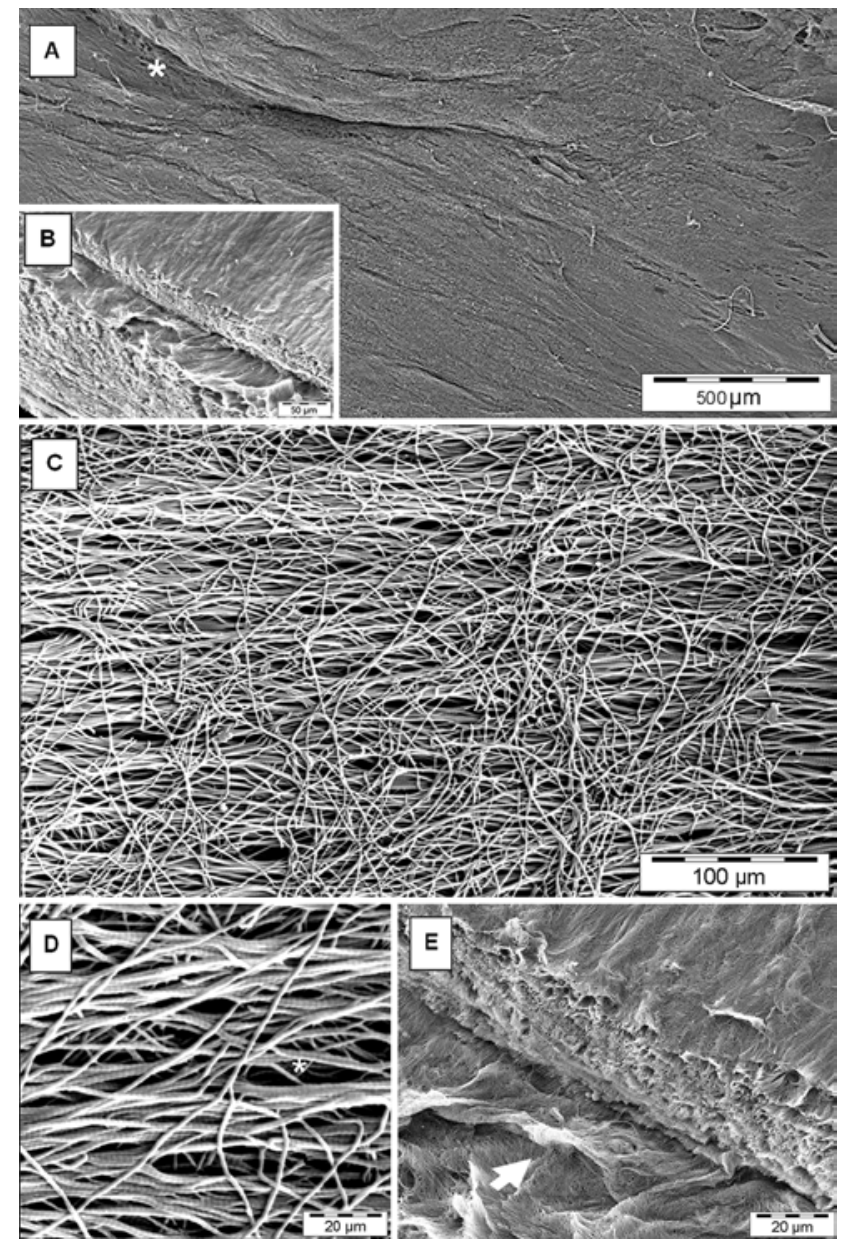

Fig. 2. A: Bone surface layer. At low magnification, it is possible to observe a continuous sheet of collagen fibers with few ridges on the surface. Among these, the deepest correspond to the meningeal vessel imprint (asterisk). B: At a higher magnification, the bone surface layer is clearly distinguished in its thickness. $\quad \mathbf{C}$ : At high magnification, the distribution of collagen fibers of the bone surface layer becomes clearly visible and one can easily distinguish the two superimposed layers. The upper layer is made of interlaced collagen fibers that form a disorganized thin net, and the lower layer is made up of bundles of collagen fibers, most of which are oriented in the same direction. D: At very high magnification, it is possible to distinguish the stripes of collagen fibers at $67 \mathrm{~nm}$ and better visualize the disposition of the 2 superimposed layers. In particular, it is possible to observe some collagen fibers running between and connecting $\mathrm{H}$-shaped collagen bundles (asterisk). E: Higher magnification of $\mathbf{B}$. The transverse section of the bone surface layer at a high magnification is easily distinguishable from the external median layer underneath. It is also possible to visualize the shape of collagen bundles lying between the external median and bone surface layers (arrow).

which is different from that of the layer above. We cannot be more precise about the orientation with respect to the cranial vault axes because the direction varies according to tensile forces of bone growth and depends on convexity curvature. What remains constant is the reciprocal distribution of the orientation of collagen fibers. The only exception is represented by the external median layer: in fact, in some specimens we cannot distinguish this layer from the vascular layer and we can recognize only a single thicker layer enclosing collagen fibers with almost
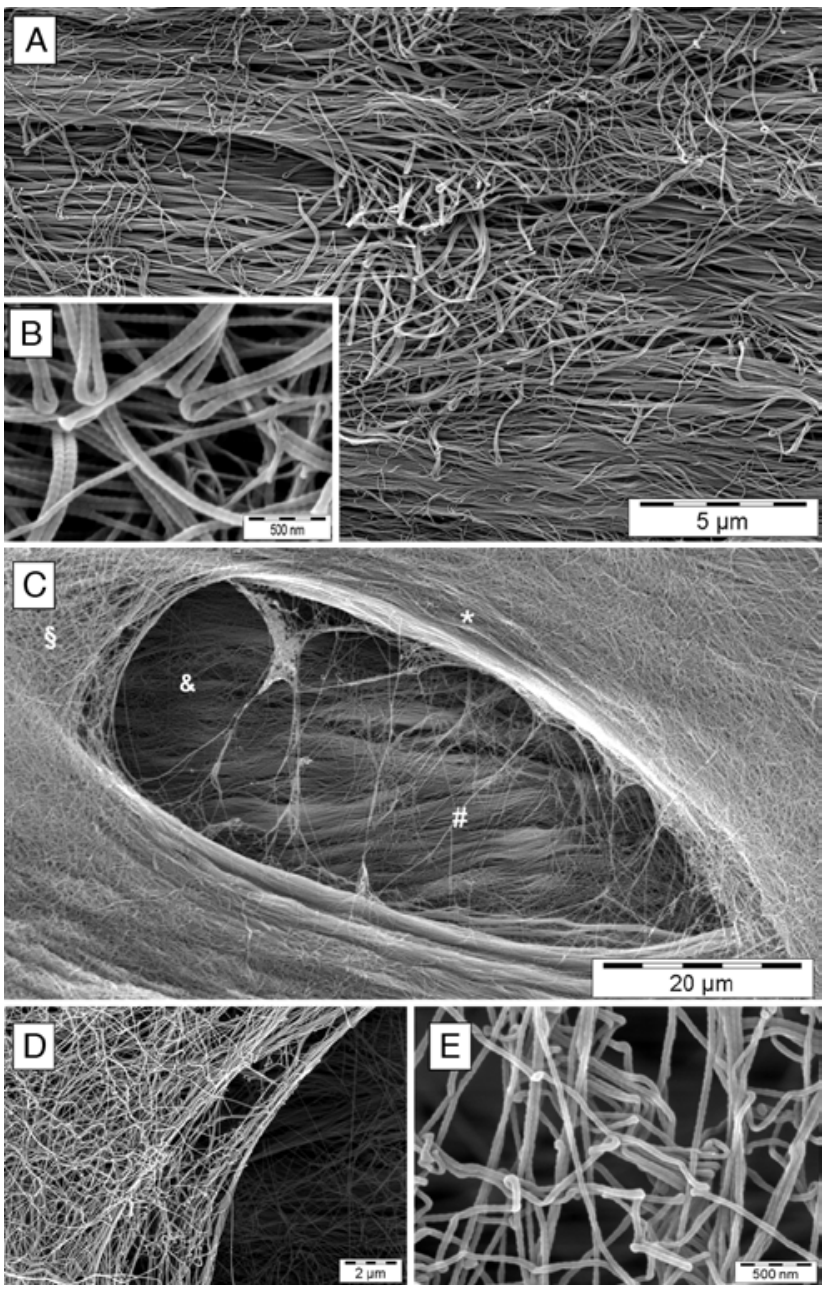

Fig. 3. Bone surface layer. A: Specialized focal aggregations of disorganized collagen fibers are clearly visible among regularly directed underlying fibers. B: At higher magnification, these fibers reveal a characteristic $180^{\circ}$-angled shape. C: Detail of a collagenic lacuna corresponding to the site occupied by fibroblast under normal conditions. Note the modification of the regular arrangement that is characteristic of the bone surface layer and the gathering of collagen fibers that line the borders of the lacuna (asterisk). Single collagen fibers run from one side to the other, sectioning the empty space (number sign). At the bottom of the hole, collagen bundles with almost the same orientation are visible (ampersand). The lacuna is partially covered by variously interlaced collagenic fibers (section symbol). D: At higher magnification, these fibers appear to be disorganized without any prevalent direction, but they form an interlaced dense net of fibers that, at very high magnification, appear tortuous and angled. E: the fibers' regular 67-nm stripes are clearly distinguished.

the same orientation. At high magnification (Fig. 4B), the external median layer is found to be made of bundles of collagen fibers all oriented along a common direction. A thin interlaced net of collagen fibers is present over these bundles, and some specialized structures seen as collagen bridges extending between and connecting these bundles are visible (Fig. 4C).

\section{Vascular Layer}

The vascular layer is the median layer of "fibrous dura" $(\gamma)$, which lies between the external median and in- 
ternal median layers (Fig. 4D). Even at low magnification, many holes are visible. The holes are more concentrated than those found in the external median layer and are clearly visible between collagen bundles. At high magnification, it is possible to see that the holes are vascular channels with a whorl-like arrangement of collagen fibrils constituting the wall (Fig. 4E). Between them, disorganized collagen fibers and thin interlaced single fibers are visible, constituting the extravascular interstitial compartment. However, the distribution and orientation of these collagen fibers reflect that of the upper external median layer.

\section{Internal Median Layer}

The internal median layer includes collagen fibers organized in bundles transversely oriented with respect to those in the upper layers (Fig. 4F). These bundles run parallel to each other. It is sometimes possible to observe a clear division between the vascular layer and the internal median layer caused by the shrinkage of collagen fibers due to tensile forces acting during the dehydration procedure. These artifacts clearly demonstrate the presence of thin and weak collagenic sheets loosely connecting them.

No significant specialized organization is observed in this layer with the exception of occasional vascular wall sections that refer to the inner dural capillary plexus.

\section{Arachnoid Layer}

The arachnoid layer is directly in contact with dural neurothelial border cells. At low magnification, the surface appears to be irregular with deep invaginations and furrows (Fig. 5A and B). At high magnification, disorganized collagen bundles with a tortuous shape are visible, forming collagenic structures without any constant orientation. Some little holes are visible among them, identifiable as capillaries belonging to the well-known plexus (Fig. 5C). At high magnification, the collagen bundles reveal their specific shape as formed by spiral collagen fibers stuck as fibers in a cord (Fig. 5D).

\section{Digital Analysis}

Digital image analysis demonstrated that, in the bone surface layer, almost all the fibers are oriented in one direction (Fig. 6A-C); however, the fibers in the arachnoid layer are oriented in many different directions (Fig. 6B and D).

\section{Discussion}

For a long time, the structure of the dura mater has been described in 2 different ways. Neurosurgeons view it as a double fibrous layer of collagen fibers adherent to the entire internal skull surface, whereas anatomists, using microscopic investigations, distinguish 3 different layers. ${ }^{28,29}$

As a matter of fact, during surgical procedures it is possible to see and distinguish, while gently opening the dura mater, its 2 layers, but when observed under a light microscope 3 layers are clearly evident. These are called outer dural cells, fibrous dura, and dural border cells facing the arachnoid membrane.
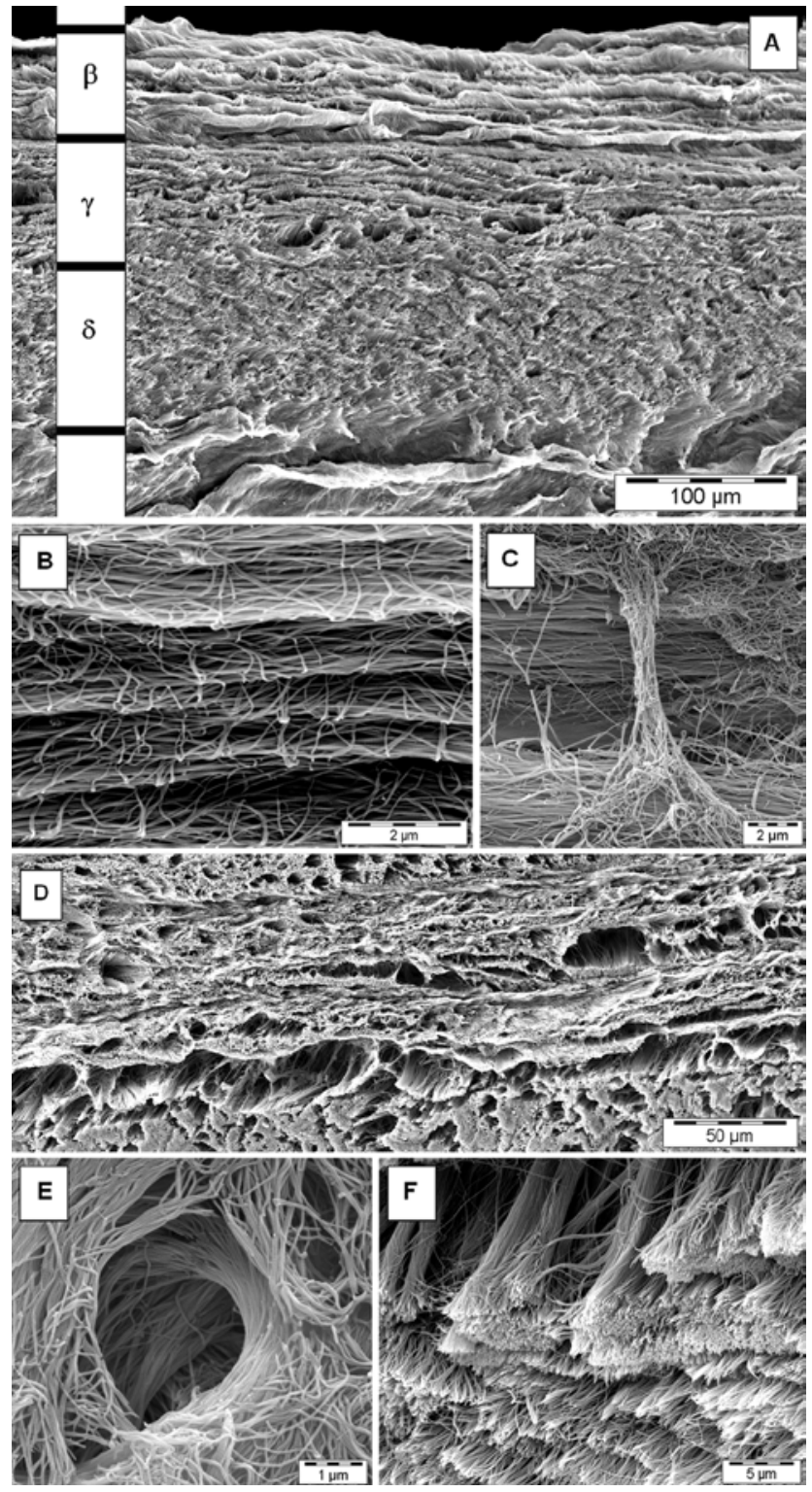

FIG. 4. Transverse section of the dura mater. The major fibrous collagenic component of the median layers is seen using the $1 \mathrm{~N} \mathrm{NaOH}$ maceration method and scanning electron microscopy. A: At low magnification, these fibers, depending on their reciprocal direction and arrangements, are clearly subdivided into 3 different layers: the external median layer $(\beta)$, the vascular layer $(\gamma)$, and the internal median layer (ठ). B: At high magnification, the external median layer is noted to be made of bundles of collagen fibers all oriented in a signal direction. C: A thin interlaced net of collagen fibers is present over these bundles, and some specialized structures seen as collagen bridges extending between and connecting these bundles are visible. D and E: In the transverse section, the vascular layer is characterized by vascular collagenic channels (D) that at high magnification (E) are noted to be composed of fibers arranged in a whorl-like pattern. F: The internal median layer is clearly distinguishable from the upper layer because of the direction of the collagen fibers that appear to be organized in collagen bundles that are all oriented in the same direction.

Despite its apparently simple structure, dura mater has multiple biomechanical and physical properties that guarantee the protection of intracranial structures, CSF turnover, and drainage of venous blood from the brain. 

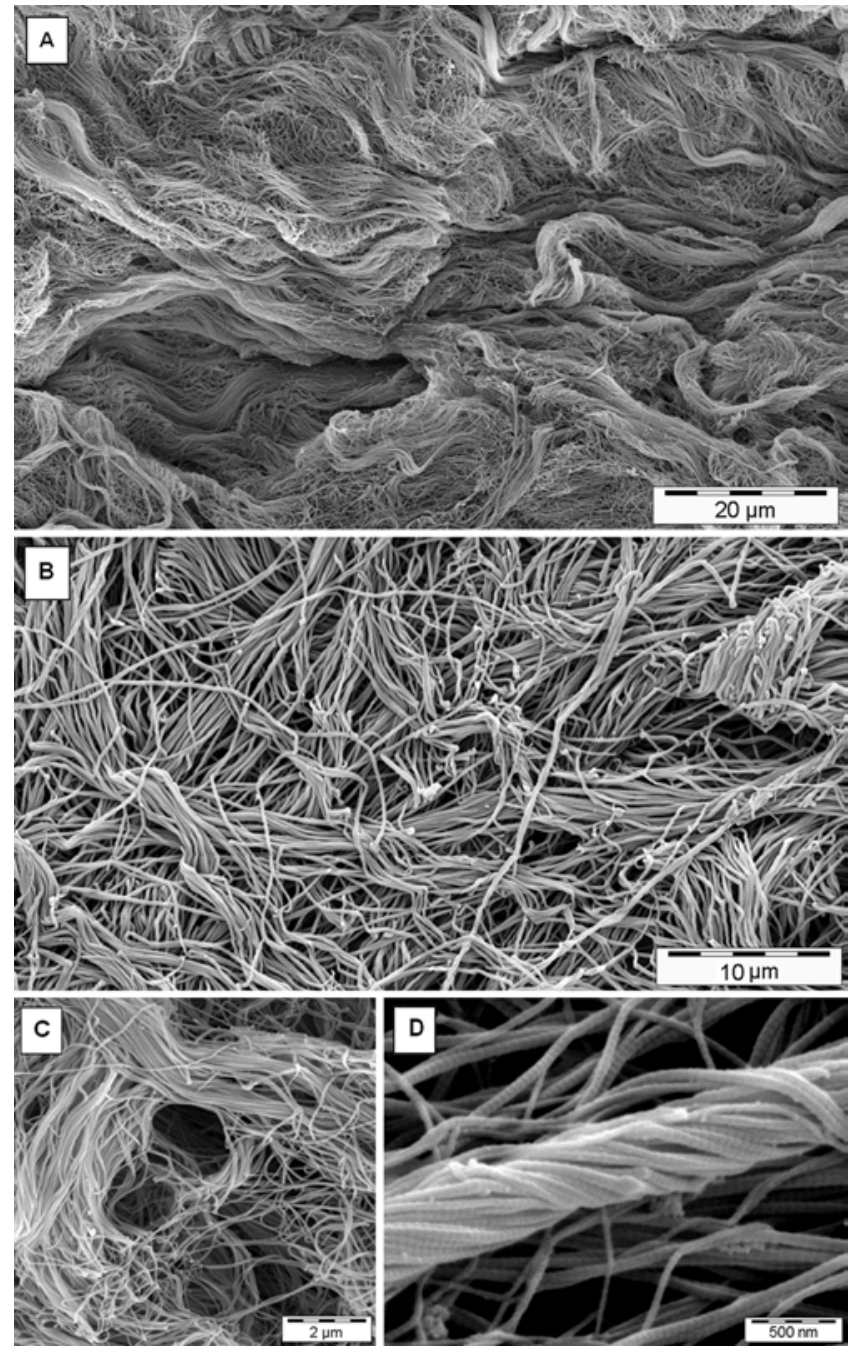

FIG. 5. The arachnoid layer appears to be characterized by a disorganized disposition of collagen bundles (low magnification). Collagen fibers are tortuous and are not oriented in any common direction. A and B: The final effect is a corrugated surface with deep invaginations and furrows. $\quad \mathbf{C}$ and $\mathbf{D}$ : At higher magnification, small holes, probably due to the signs of a capillary plexus (C), and bundles of spiral collagen fibers (D) are visible.

This, along with the increasing need to repair dural defects due to surgical procedures or traumatic injuries, has always driven the scientific interest in reproducing the same morphological characteristics in an "ideal" substitute that could mimic the physical and biological features of dura mater itself. As yet, however, no detailed report is available regarding the $3 \mathrm{D}$ architecture, disposition and orientation of collagen fibers, and the number of layers in human cranial dura mater.

We have analyzed specimens from surgical decompression procedures performed in patients affected by brain swelling or traumatic brain injuries. We have analyzed fresh human specimens to avoid any bias caused by artifacts that are commonly observed in cadaver specimens due to conservation, and we focused our attention on the major components of dura mater, that is, collagen fibers, with a goal of describing its 3D disposition and
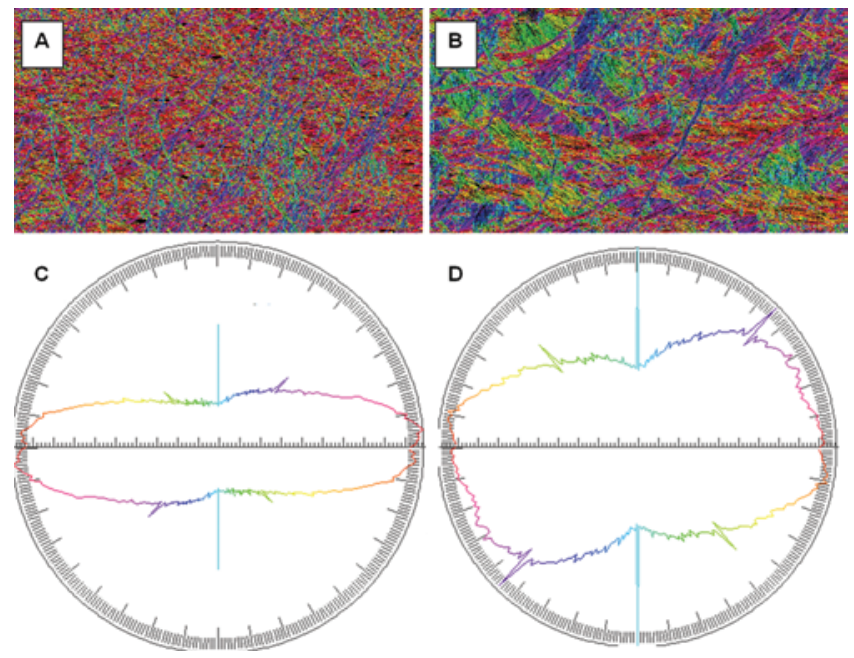

Fig. 6. A and B: Colorimetric analysis of the bone surface layer (A) compared with that of the arachnoidal layer (B). C and D: Graphs demonstrating the predominance of a single direction of collagen fibers in the bone surface layer $(\mathrm{C})$ and the various directions of the collagen fibers visible in the arachnoid layer (D).

architectural organization. Therefore, we decided to use the $1 \mathrm{~N} \mathrm{NaOH}$ maceration method and observation with scanning electron microscopy to obtain 3D data regarding collagen fiber shape, disposition, and orientation without interference of other organic (cellular or vascular nervous structure) components. ${ }^{20}$ The $1 \mathrm{~N} \mathrm{NaOH}$ scanning electon microscopy investigation technique is a commonly used method to study the collagenic component of many tissues and organs in normal and pathological conditions. 7,21,22,26,27

In terms of clinical application, this technique is quite similar to that recommended by the WHO (1992) $\left(1 \mathrm{~N} \mathrm{NaOH}\right.$ for 1 hour at $20^{\circ} \mathrm{C}$ ) for prion inactivation for allografts. Other techniques can be used for this purpose, such as sodium hypochlorite $2 \%$ for 1 hour at $20^{\circ} \mathrm{C}$ or autoclaving at $132^{\circ} \mathrm{C}$ for 1 hour, but $\mathrm{NaOH}$ maceration is chosen because it is the only technique that really preserves the collagen structure of the allograft. At the end of this treatment, the goal is to obtain a collagenic allograft that has a very low risk of conventional and unconventional agent transmission without losing its 3D collagenic architecture. As previously stated, dura mater has always been considered to be composed of 2 or 3 layers. Using this technique, we were able to observe 5 different layers of dura mater, distinguishable mainly based on the distribution and reciprocal direction of collagen fibers.

However, it is not possible to precisely define the orientation of the fibers with respect to the cranial vault axis for 2 main reasons. First, the vault axis varies according to tensile forces of bone growth and its curvature. What remains constant is the reciprocal distribution of the orientation of collagen fibers in each layer. Second, even if the orientation of collagen fibers varies depending on the layer observed, visualization of these fibers, with the exception of those in the bone surface and arachnoid layers, also depends on how the specimens were cut. For these reasons, only the reciprocal directions of the fibers can be taken into account. 
Following our analysis, the outermost layer that is in direct contact with the internal surface of the skull has been named the bone surface layer. The median layer, previously identified by anatomists as fibrous dura, has been divided into 3 layers: the external, vascular, and internal layers. The innermost layer directly in contact with dural border cells has been named the arachnoid layer.

It is widely known that physical characteristics such as tensile strength and resistance to tearing forces strictly depend on the orientation of collagen fibers. Such fibers provide the dura mater with all its mechanical features and form the basis of its multiple characteristics. For these reasons, we particularly focused our attention on this aspect using scanning electron microscopy analysis software that is able to analyze the distribution of the entire length of the collagen fibers in each layer.

The bone surface layer is very regular even if the contact with bone would suggest a more disorganized shape. This flat layer probably represents the basal membrane of a limiting fibroblast sheet that guarantees the attachment to bone tissue. Computerized colorimetric examination of this layer revealed a single common direction of collagen fibers.

Collagen fibers in the median layer are variously arranged in 3 dimensions forming 3 different layers: the external, vascular, and internal median layers. The change in the direction of the collagen fibers is mostly visible between the vascular and internal median layers. Therefore, this site is subjected to the highest stretching forces representing a locus minoris resistentiae that allows neurosurgeons to distinguish dura mater into 2 layers. In the vascular layer, it is possible to see how the collagen fibers that make up the dura mater also provide the organic scaffold to cellular components (fibroblasts, vessels, and nerve endings). Fibroblasts are enclosed in collagenic lacunae well visible from the bone surface layer and in median layers. Connection with dural border cells and the passage to the arachnoid layer is evident by the presence of the loosely composed arachnoid layer. This layer is characterized by large bundles of collagen causing a corrugated layer already visible at low magnification. Computerized colorimetric analysis demonstrates a wide distribution of the fibers in all directions without any prevalent orientation.

\section{Conclusions}

This study focuses on the structural and ultrastructural features of the dura mater, highlighting its intrinsic collagenic structure. The $1 \mathrm{~N} \mathrm{NaOH}$ maceration method applied to scanning electron microscopy analysis has been shown to be a good investigative technique to evaluate features of the dura mater in depth. Knowledge of the disposition of its collagen fibers in 3 dimensions and their distribution along all its layers could be useful in evaluating dura mater allografts and in creating new allografts with morphological features that are more similar to the dura mater itself.

\section{Disclosure}

The authors report no conflict of interest concerning the mate- rials or methods used in this study or the findings specified in this paper.

Author contributions to the study and manuscript preparation include the following. Conception and design: Protasoni, Sangiorgi. Acquisition of data: Protasoni, Sangiorgi, Cividini, Reguzzoni, Raspanti. Analysis and interpretation of data: Protasoni, Sangiorgi, Reguzzoni, Raspanti, Tomei, Cividini. Drafting the article: Protasoni, Sangiorgi. Critically revising the article: Protasoni, Dell'Orbo, Raspanti, Balbi, Sangiorgi. Reviewed final version of the manuscript and approved it for submission: Protasoni. Administrative/technical/ material support: Culuvaris, Raspanti. Study supervision: Tomei, Dell'Orbo, Raspanti, Balbi, Reguzzoni.

\section{Acknowledgment}

The authors gratefully acknowledge the "Centro Grandi Attrezzature per la Ricerca Biomedica" of Insubria University for use of the instruments.

\section{References}

1. Alcolado R, Weller RO, Parrish EP, Garrod D: The cranial arachnoid and pia mater in man: anatomical and ultrastructural observations. Neuropathol Appl Neurobiol 14:1-17, 1988

2. Barbolt TA, Odin M, Léger M, Kangas L, Hoiste J, Liu SH: Biocompatibility evaluation of dura mater substitutes in an animal model. Neurol Res 23:813-820, 2001

3. Benini A, Bonar SK: Andreas Vesalius 1514-1564. Spine 21: 1388-1393, 1996

4. Biroli F, Fusco M, Bani GG, Signorelli A, Esposito F, de Divitiis $\mathrm{O}$, et al: Novel equine collagen-only dural substitute. Neurosurgery 62 (3 Suppl 1):273-274, 2008

5. Chaplin JM, Costantino PD, Wolpoe ME, Bederson JB, Griffey ES, Zhang WX: Use of an acellular dermal allograft for dural replacement: an experimental study. Neurosurgery 45:320-327, 1999

6. Collins RL, Christiansen D, Zazanis GA, Silver FH: Use of collagen film as a dural substitute: preliminary animal studies. J Biomed Mater Res 25:267-276, 1991

7. Conegero CI, Chopard RP: Tridimensional architecture of the collagen element in the arachnoid granulation in humans: a study on scanning electron microscopy. Arq Neuropsiquiatr 61:561-565, 2003

8. Costantino PD, Wolpoe ME, Govindaraj S, Chaplin JM, Sen C, Cohen M, et al: Human dural replacement with acellular dermis: clinical results and a review of the literature. Head Neck 22:765-771, 2000

9. Fricke B, Andres KH, Von Düring M: Nerve fibers innervating the cranial and spinal meninges: morphology of nerve fiber terminals and their structural integration. Microsc Res Tech 53:96-105, 2001

10. Gök A, Zorludemir S, Polat S, Tap O, Kaya M: Experimental evaluation of peritoneum and pericardium as dural substitutes. Res Exp Med (Berl) 195:31-38, 1995

11. Knopp U, Christmann F, Reusche E, Sepehrnia A: A new collagen biomatrix of equine origin versus a cadaveric dura graft for the repair of dural defects-a comparative animal experimental study. Acta Neurochir (Wien) 147:877-887, 2005

12. Laquerriere A, Yun J, Tiollier J, Hemet J, Tadie M: Experimental evaluation of bilayered human collagen as a dural substitute. J Neurosurg 78:487-491, 1993

13. Maher CO, Anderson RE, McClelland RL, Link MJ: Evaluation of a novel propylene oxide-treated collagen material as a dural substitute. J Neurosurg 99:1070-1076, 2003

14. Manelli A, Sangiorgi S, Binaghi E, Raspanti M: 3D analysis of SEM images of corrosion casting using adaptive stereo matching. Microsc Res Tech 70:350-354, 2007

15. Meddings N, Scott R, Bullock R, French DA, Hide TA, Gorham SD: Collagen vicryl-a new dural prosthesis. Acta Neurochir (Wien) 117:53-58, 1992 
16. Nabeshima S, Reese TS, Landis DM, Brightman MW: Junctions in the meninges and marginal glia. J Comp Neurol 164: $127-169,1975$

17. Narotam PK, José S, Nathoo N, Taylon C, Vora Y: Collagen matrix (DuraGen) in dural repair: analysis of a new modified technique. Spine 29:2861-2869, 2004

18. Narotam PK, Van Dellen JR, Bhoola K, Raidoo D: Experimental evaluation of collagen sponge as a dural graft. Br $\mathbf{J}$ Neurosurg 7:635-641, 1993

19. Nordstrom MR, Wang TD, Neel HB III: Dura mater for softtissue augmentation. Evaluation in a rabbit model. Arch Otolaryngol Head Neck Surg 119:208-214, 1993

20. Ohtani O: The maceration technique in scanning electron microscopy of collagen fiber frameworks: its application in the study of human livers. Arch Histol Cytol 55 (Suppl): 225-232, 1992

21. Ohtani O: Three-dimensional organization of the connective tissue fibers of the human pancreas: a scanning electron microscopic study of $\mathrm{NaOH}$ treated-tissues. Arch Histol Jpn 50:557-566, 1987

22. Ohtani O, Ushiki T, Taguchi T, Kikuta A: Collagen fibrillar networks as skeletal frameworks: a demonstration by cellmaceration/scanning electron microscope method. Arch Histol Cytol 51:249-261, 1988

23. Pease DC, Schultz RL: Electron microscopy of rat cranial meninges. Am J Anat 102:301-321, 1958

24. Runza M, Pietrabissa R, Mantero S, Albani A, Quaglini V, Contro R: Lumbar dura mater biomechanics: experimental characterization and scanning electron microscopy observations. Anesth Analg 88:1317-1321, 1999

25. Sakas DE, Charnvises K, Borges LF, Zervas NT: Biologically inert synthetic dural substitutes. Appraisal of a medical-grade aliphatic polyurethane and a polysiloxane-carbonate block copolymer. J Neurosurg 73:936-941, 1990

26. Sangiorgi S, Manelli A, Dell'Orbo C, Congiu T: A new method for the joint visualization of vascular structures and con- nective tissues: corrosion casting and $1 \mathrm{~N} \mathrm{NaOH}$ maceration. Microsc Res Tech 69:919-923, 2006

27. Sangiorgi S, Manelli A, Protasoni M, Ronga M, Raspanti M: The collagenic structure of human digital skin seen by scanning electron microscopy after Ohtani maceration technique. Ann Anat 187:13-22, 2005

28. Shukla V, Hayman LA, Ly C, Fuller G, Taber KH: Adult cranial dura I: intrinsic vessels. J Comput Assist Tomogr 26: 1069-1074, 2002

29. Shukla V, Hayman LA, Taber KH, Fuller G, Taber KH: Adult cranial dura II: venous sinuses and their extrameningeal contributions. J Comput Assist Tomogr 27:98-102, 2003

30. Vandenabeele F, Creemers J, Lambrichts I: Ultrastructure of the human spinal arachnoid mater and dura mater. J Anat 189:417-430, 1996

31. Viñas FC, Ferris D, Kupsky WJ, Dujovny M: Evaluation of expanded polytetrafluoroethylene (ePTFE) versus polydioxanone (PDS) for the repair of dura mater defects. Neurol Res 21:262-268, 1999

32. Warren WL, Medary MB, Dureza CD, Bellotte JB, Flannagan PP, Oh MY, et al: Dural repair using acellular human dermis: experience with 200 cases: technique assessment. Neurosurgery 46:1391-1396, 2000

33. Weller RO: Microscopic morphology and histology of the human meninges. Morphologie 89:22-34, 2005

Manuscript submitted October 11, 2010.

Accepted December 8, 2010.

Please include this information when citing this paper: published online February 4, 2011; DOI: 10.3171/2010.12.JNS101732.

Address correspondence to: Marina Protasoni, M.D., Ph.D., Department of Human Morphology, University of Insubria, Via Monte Generoso 71, 21100 Varese, Italy. email: marina.protasoni@ uninsubria.it. 